\title{
Comparison of Opioid Prescribing Patterns in the United States and Japan: Primary Care Physicians' Attitudes and Perceptions
}

\author{
Eriko Onishi, MD, Tadashi Kobayashi, MD, PhD, Eve Dexter, MS, \\ Miguel Marino, PhD, Tetsubiro Maeno, MD, PhD, and Richard A. Deyo, MD, MPH
}

Introduction: Far fewer opioids are prescribed in Japan than in the United States.

Methods: We conducted an online physician survey assessing attitudes and perceptions that might influence prescribing. A Japanese version was distributed to members of the Japan Primary Care Association and an English version to members of the American Academy of Family Physicians practicing in Oregon.

Results: We received 461 Japanese responses and 198 from the United States, though overall response rates were low (Japan: 10.1\%, United States: 18.5\%). Japanese respondents reported far less opioid prescribing than US respondents, especially for acute pain (acute pain: $49.4 \%$ vs $97.0 \%$; chronic pain: $63.7 \%$ vs $90.9 \% ; P<.001$ for both). Almost half of respondents from both countries indicated that patient expectations and satisfaction were important factors that influence prescribing. US respondents were significantly more likely to identify medical indication and legal expectation as reasons to prescribe opioids for acute pain. Most US respondents (95.4\%) thought opioids were used too often, versus 6.6\% of Japanese respondents.

Conclusions: Lower opioid use was reported in Japan, especially for acute pain, which may help minimize long-term use. Patient expectations and satisfaction seem to influence opioid prescribing in both countries. The United States could learn from Japanese regulatory and cultural perspectives. ( $\mathrm{J}$ Am Board Fam Med 2017;30:248-254.)

Keywords: Acute Pain, Chronic Pain, Japan, Opioid Analgesics, Opioid-Related Disorders, Oregon, Prescriptions, Primary Health Care, Surveys and Questionnaires

Opioid prescribing has increased worldwide, with opioid sales in the United States quadrupling between 1999 and 2010. ${ }^{1}$ As opioid sales have grown,

This article was externally peer reviewed.

Submitted 17 September 2016; revised 13 December 2016; accepted 23 December 2016.

From the Department of Family Medicine, Oregon Health \& Science University, Portland (EO, ED, MM, RAD); the Department of General Medicine, Hirosaki University School of Medicine \& Hospital, Hirosaki, Aomori Prefecture, Japan (TK); the Department of Public Health and Preventive Medicine, Oregon Health \& Science University, Portland (MM, RAD); the Department of Primary Care and Medical Education, University of Tsukuba, Tsukuba, Ibaraki Prefecture, Japan (TM); and the Oregon Institute for Occupational Health Science, Oregon Health \& Science University, Portland (RAD).

Funding: none.

Conflict of interest: none declared.

Corresponding author: Eriko Onishi, MD, Department of Family Medicine, Oregon Health \& Science University, 3181 SW Sam Jackson Park Rd, FM, Portland, OR 97239 (E-mail: onishi@ohsu.edu). admissions to substance treatment programs and opioid-related overdose deaths have also increased fourfold. ${ }^{1,2}$ It is estimated that, in the United States, 1 person dies every 36 minutes from opioid overdose. ${ }^{3}$ The increased supply of prescription opioids, use of high-dose opioids, "doctor shopping" phenomena, and patients with multiple comorbid conditions may all contribute to these fatalities. $^{4}$

The largest volume of opioids is prescribed for chronic pain. In one US health plan, $87 \%$ of all morphine equivalents for pain were dispensed to patients receiving long-term opioids. ${ }^{5}$ However, the long-term effectiveness of opioids for chronic pain is limited, and complications are increasingly well documented. ${ }^{6}$ No randomized trials have lasted beyond 4 months, and most have excluded patients with a history of either substance misuse or 
mental disorders. ${ }^{7,8}$ The mean magnitude of shortterm pain relief across a spectrum of chronic noncancer pain conditions is roughly $30 \%$. $^{9}$

Systematic reviews largely agree that opioids have a greater short-term analgesic efficacy than placebo, but benefits for function and long-term pain relief are less clear. ${ }^{7-9}$ Opioid prescribing in acute injury is associated with longer work disability and worse function after 6 months. ${ }^{8}$ If prescribers provide a large supply or simply continue to refill prescriptions, prescribing opioids for acute pain may inadvertently lead to drug dependence and long-term use. ${ }^{8,10}$

There is substantial geographic variation in opioid prescribing. Per capita use of 6 potent opioids is 26 times higher in the United States compared with Japan. ${ }^{8}$ Until the last couple of decades, Japan had not experienced problems with opioid addiction. ${ }^{11}$ In the early 19th century, Japan was the first Asian country to enact legislation to control opioid use, and it is still severely restricted. ${ }^{11}$ Social and legal factors in general, and the criminal justice and health care systems, have played key roles in both countries' patterns of use. ${ }^{11}$

Point-prevalence estimates of chronic pain from population-based surveys vary widely, with worldwide estimates ranging from $2 \%$ to over $55 \% .{ }^{12}$ In the United States, the prevalence was $30.7 \%$ in a 2008 to 2009 Internet survey that defined chronic pain as "persistent pain of more than 6 months."12 A 2011 survey in an industrialized community in Japan estimated that the prevalence of chronic pain, defined as "persistent pain of more than 3 months," was $39.3 \% .^{13}$ Thus, chronic pain seems to be a major problem in both countries.

Mindful of US-Japanese differences in the volume of opioid prescribing, cultural differences, and the public health impact of opioid use in the United States, we sought to explore beliefs and attitudes regarding opioid prescribing among primary care physicians in both countries. What factors affect prescribing behaviors? What are physicians' beliefs regarding use of opioids? Examining and comparing physician behaviors and beliefs, as well as differing professional standards, may help to inform physicians and the public alike about better pain management and prescribing practices.

\section{Methods}

The research was approved by the institutional review board of Oregon Health and Science Uni- versity in the United States and by the medical ethics committee of Hirosaki University School of Medicine \& Hospital in Japan.

\section{Questionnaire Development}

One of us (EO, a Japanese-born and Japan-trained family physician practicing in the United States) developed a novel survey of physician attitudes and beliefs regarding opioid prescribing. An English version was pilot tested with 13 family physicians in a US academic practice, resulting in a revised English version. The same author translated this into a Japanese version, which was further refined by Japanese physicians (TK, TM). This second Japanese version was back-translated to develop a final English version of the survey. Discrepancies were resolved and a final Japanese version was prepared. The Japanese and English questionnaires can be viewed at https://octri.ohsu.edu/redcap/surveys/ ?s=mWGqIy8YSH and https://octri.ohsu.edu/ redcap/surveys/?s=Sef9Nt7vaK, respectively.

\section{Questionnaire Content}

We considered use of opioids for both acute and chronic pain. For acute pain, we described 2 patient scenarios in a clinical outpatient setting: acute pain from a nonobstructed kidney stone and acute pain from a sprained joint. Patients with chronic pain conditions were described as those with chronic nonspecific back pain, osteoarthritis of any joint, fibromyalgia, or other similar conditions. We did not define the duration of chronic pain. We assessed factors that might influence respondents' opioid prescribing (eg, perception as to whether medically indicated, standard of care, patient expectations, maintaining patient satisfaction, legal expectations).

The surveys included questions regarding physicians' age and sex, the type and frequency of drug use in treating acute and chronic pain, and their opinions regarding use of opioids. Physicians were asked to rate their frequency of using the following opioids in treating both acute and chronic pain: tramadol alone or in combination with acetaminophen; codeine, hydrocodone, or oxycodone with or without acetaminophen; buprenorphine; pentazocine (any route of administration); or morphine, fentanyl, methadone, or hydromorphone (any route of administration). Frequency was rated on a 5-point Likert scale (all the time, frequently, occasionally, seldom, never). 
Questions concerning factors that might influence opioid prescribing for acute pain and chronic pain were assessed on a 5-point Likert scale (strongly agree, agree, neutral, disagree, strongly disagree). Respondents' perceptions of opioid prescribing patterns in their own countries were assessed as "opioids are used too often," "just about right," or "too seldom."

\section{Data Collection}

The survey was conducted online using secure survey software (RedCap). The Japanese survey was presented to members of the Japan Primary Care Association (JPCA). It was E-mailed simultaneously to all active JPCA members, and reminders were sent 4 times during July to September 2014. The US survey was E-mailed to active members of the American Academy of Family Physicians (AAFP) in Oregon. US reminders were sent 3 times during December 2014 to February 2015.

\section{Data Analysis}

The $\chi^{2}$ test and Fisher exact test (when appropriate) were used to compare demographics of and frequency of opioid use (dichotomized into never/ seldom vs occasionally to all the time) among Japanese and US respondents. Factors influencing the use of opioids for acute or chronic pain and physician beliefs about opioids being indicated for chronic pain were dichotomized into strongly disagree/disagree/neutral versus agree/strongly agree. Multivariable logistic regression analysis was used to compute the odds of factors influencing the use of opioids for acute and chronic pain based on respondents' country, adjusted for differences in age and sex. The odds of physicians perceiving opioids as being indicated for chronic pain were estimated similarly. All statistical tests were 2 -sided, and significance was defined as a $P$ value $<.05$. Analyses were performed using $\mathrm{R}$ version 3.2.2 and Stata version 12.

\section{Results}

\section{Study Sample}

We received 461 responses from a pool of 4552 JPCA members $(10.1 \%)$ and 198 responses from 1067 active AAFP members (18.5\%). Of the Japanese respondents, 26 (5.4\%) indicated they did not have the necessary opioid prescribing license; thus 435 responses were analyzed. All US respondents reported they had the necessary license to prescribe opioids.

Japanese respondents comprised a greater proportion of men $(83.6 \%$ Japan vs $51.0 \%$ US; $P<$ $.001)$ and respondents younger than age 40 (43.0\% Japan vs $28.9 \%$ US; $P<.001)$.

\section{Self-Reported Opioid Prescribing}

Opioid use was reported significantly less often in Japan than in the US for both acute and chronic pain (Table 1). Overall, 24.1\% of Japanese respondents reported that they would 'never' or 'seldom' use opioids for acute or chronic pain, compared with $1.0 \%$ of US physicians $(P<.001)$.

When prescribing opioids for acute pain, US respondents were significantly more likely than Japanese respondents to rate medical indications, standard of care, and legal expectations as factors that influence prescribing (Table 2). As an example, $27.3 \%$ of Japanese respondents indicated that opioid therapy was a standard of care for acute pain, versus $66.0 \%$ of US respondents (adjusted odds ratio [aOR], 4.57; $P<.001)$. Close to half of both US and Japanese respondents cited patient expectations or patient satisfaction as factors that influence opioid prescribing for acute pain (Table 2).

In prescribing opioids for chronic pain, more than half of respondents from both countries indicated that patient expectations and satisfaction were factors that influence prescribing (Table 3 ). US respondents were more likely to indicate that opioid therapy was a standard of care for chronic pain $(56.0 \%$ US vs $42.9 \%$ Japan; aOR, $1.60 ; P=$ $.023)$. Similarly, US respondents were twice as likely as Japanese physicians to indicate that opioid treatment was a legal expectation $(17.6 \%$ US vs 8.6\% Japan; aOR, 2.03; $P=.026$ ) (Table 3).

\section{Beliefs Regarding Opioid Use}

US respondents were less likely than Japanese respondents to believe opioids were indicated for chronic pain when nonopioid medications and other modalities were ineffective $(58.7 \%$ US vs 73.9\% Japan; odds ratio, $0.51 ; P<.001$ ) (Table 1 ). US respondents were far more likely than Japanese to believe opioids are used too often in their own country (95.4\% US vs 6.6\% Japan; $P<.001)$ (Table 1). 
Table 1. Demographic Characteristics of Survey Respondents and Self-Reported Frequency of Opioid* Prescribing

\begin{tabular}{|c|c|c|c|}
\hline & $\begin{array}{l}\text { Japanese Respondents } \\
\qquad(\mathrm{n}=435)^{\dagger}\end{array}$ & $\begin{array}{l}\text { US Respondents } \\
\quad(\mathrm{n}=198)\end{array}$ & $P$ Value $^{\ddagger}$ \\
\hline Sex & & & $<.001$ \\
\hline Female & $70(16.4)$ & $96(49.0)$ & \\
\hline Male & $358(83.6)$ & $100(51.0)$ & \\
\hline Age (years) & & & $<.001$ \\
\hline$<40$ & $184(43.0)$ & $57(28.9)$ & \\
\hline $41-50$ & $132(30.8)$ & $64(32.5)$ & \\
\hline $51-60$ & $95(22.2)$ & $54(27.4)$ & \\
\hline$>60$ & $17(1.0)$ & $22(11.2)$ & \\
\hline Use opioids to control acute pain ${ }^{\S}$ or chronic pain $\|$ & & & $<.001^{\text {II }}$ \\
\hline Never/seldom & $105(24.1)$ & $2(1.0)$ & \\
\hline Occasionally to all the time & $330(75.9)$ & $196(99.0)$ & \\
\hline Use opioids to control acute pain & & & $<0.001$ \\
\hline Never/seldom & $220(50.6)$ & $6(3.0)$ & \\
\hline Occasionally to all the time & $215(49.4)$ & $192(97.0)$ & \\
\hline Use opioids to control chronic pain & & & $<.001$ \\
\hline Never/seldom & $158(36.3)$ & $18(9.1)$ & \\
\hline Occasionally to all the time & $277(63.7)$ & $180(90.9)$ & \\
\hline Frequency of opioid use in own country ${ }^{* *}$ & & & $<.001$ \\
\hline Seldom/just right & $396(93.4)$ & $9(4.6)$ & \\
\hline Too often & $28(6.6)$ & $187(95.4)$ & \\
\hline Opioids are indicated for chronic pain ${ }^{\dagger \dagger}$ & $317(73.9)$ & $115(58.7)$ & $<.001^{\text {f+ }}$ \\
\hline
\end{tabular}

Data are $\mathrm{n}(\%)$. Totals may vary because some respondents did not complete all parts of the questionnaires.

*Opioids include tramadol, codeine, buprenorphine, pentazocine, morphine, fentanyl, methadone, and hydromorphone.

${ }^{\dagger} \mathrm{A}$ total of 461 responses were received, but 26 respondents (5.4\%) had no opioid prescribing license, leaving 435 prescribers to analyze.

${ }^{\ddagger} P$ values from a $\chi^{2}$ test unless otherwise specified.

${ }^{\$}$ Acute pain includes acute nonobstructing kidney stones and sprain or strain of any joint.

"Chronic pain includes chronic nonspecific back pain, osteoarthritis of any joint, fibromyalgia, or other, similar conditions.

II $P$ value from Fisher exact test because of the small cell size.

${ }^{* *}$ Personal belief that opioids are used too seldom/used just right versus opioids are used too often.

${ }^{{ }^{\dagger}}$ Very strongly/strongly/mildly agree versus neutral/disagree/strongly disagree.

${ }^{\ddagger \ddagger} P$ values for adjusted odds ratios.

\section{Discussion}

Few studies have compared beliefs about and attitudes toward opioid prescribing among physicians from countries with sharply contrasting rates of opioid use. It seems that US respondents consider opioids to be the standard of care for both acute and chronic pain more often than their Japanese counterparts. For acute pain in particular, US respondents were more likely than those in Japan to see opioid treatment as both medically indicated and the standard of care.

Part of the international difference is likely related to different health care systems. Japan has a national insurance system, and indications for each medication are strictly followed because insurance plans will not provide coverage otherwise. For example, insurance covers the use of oxycodone only for cancer pain, so it cannot be prescribed for other types of pain. In addition, a tramadol-acetaminophen combination is covered only for noncancer pain and tooth extraction. While codeine, morphine, fentanyl patches, and buprenorphine are covered for both cancer and noncancer pain, ${ }^{14}$ physician prescribing for chronic noncancer pain must meet several criteria ${ }^{15}$ :

1. The physician must have completed lengthy E-learning modules for each specific opioid.

2. Both physician and patient must sign a contractual agreement upon initiating opioid treatment.

3. The patient must be taking nonopioid analgesics before opioids are initiated. 
Table 2. Physician Self-Report of Factors That Influence Opioid Prescribing for Acute Pain in the United States and Japan

\begin{tabular}{|c|c|c|c|}
\hline & Agree/Strongly Agree, n (\%) & $\mathrm{OR}^{*}(95 \% \mathrm{CI})$ & $P$ Value $^{\dagger}$ \\
\hline \multicolumn{4}{|c|}{ Medically indicated } \\
\hline Japan & $130(52.6)$ & 1.00 (ref) & - \\
\hline United States & $168(86.6)$ & $5.33(3.15-9.05)$ & $<.001$ \\
\hline Standard of care & & 1.00 (ref) & \\
\hline Japan & $66(27.3)$ & $4.57(2.91-7.17)$ & - \\
\hline United States & $128(66.0)$ & & $<.001$ \\
\hline \multicolumn{4}{|c|}{ Patient expectation } \\
\hline Japan & $121(49.2)$ & 1.00 (ref) & - \\
\hline United States & $89(45.9)$ & $0.94(0.62-1.44)$ & .790 \\
\hline \multicolumn{4}{|c|}{ Maintaining patient satisfaction } \\
\hline Japan & $119(48.4)$ & 1.00 (ref) & - \\
\hline United States & $98(50.8)$ & $1.22(0.80-1.87)$ & .360 \\
\hline \multicolumn{4}{|l|}{ Legal expectation } \\
\hline Japan & $16(6.6)$ & 1.00 (ref) & - \\
\hline United States & $29(15.1)$ & $2.47(1.22-5.04)$ & .012 \\
\hline
\end{tabular}

*Odds ratios (ORs) were estimated from logistic regression models that adjusted for sex (female, male) and age category $(<40,41-50$, $51-60,>60$ years).

${ }^{\dagger} P$ values for adjusted odds ratios.

$\mathrm{CI}$, confidence interval; ref, reference category.

4. The patient must undergo trial use of a challenge opioid to ensure effectiveness before advancing to chronic use.

It is burdensome to store opioids in clinics and pharmacies because Japan has strict storage rules under the Narcotics and Psychotropic Control Law. This, combined with the rare use of opioids, means that many clinics and pharmacies choose not to stock them at all. Driving is strictly prohibited while under the influence of opioids under Japan's Road Traffic Act. Given the current epidemic of

Table 3. Self-Report of Factors That Influence Opioid Prescribing for Chronic Pain in the United States and Japan

\begin{tabular}{|c|c|c|c|}
\hline & Agree/Strongly Agree, n (\%) & $\mathrm{OR}^{*}(95 \% \mathrm{CI})$ & $P$ Value $^{\dagger}$ \\
\hline \multicolumn{4}{|c|}{ Medically indicated } \\
\hline Japan & $211(69.2)$ & 1.00 (ref) & - \\
\hline United States & $146(75.6)$ & $1.29(0.83-2.03)$ & .260 \\
\hline \multicolumn{4}{|l|}{ Standard of care } \\
\hline Japan & $130(42.9)$ & 1.00 (ref) & - \\
\hline United States & $107(56.0)$ & $1.60(1.07-2.39)$ & .023 \\
\hline \multicolumn{4}{|c|}{ Patient expectation } \\
\hline Japan & $193(63.1)$ & 1.00 (ref) & - \\
\hline United States & $109(56.5)$ & $0.83(0.55-1.25)$ & .380 \\
\hline \multicolumn{4}{|c|}{ Maintaining patient satisfaction } \\
\hline Japan & $201(65.3)$ & 1.00 (ref) & - \\
\hline United States & $103(53.6)$ & $0.68(0.45-1.02)$ & .061 \\
\hline \multicolumn{4}{|l|}{ Legal expectation } \\
\hline Japan & $25(8.6)$ & 1.00 (ref) & - \\
\hline United States & $33(17.6)$ & $2.03(1.09-3.77)$ & .026 \\
\hline
\end{tabular}

* Odds ratios (ORs) estimated from logistic regression models that adjusted for sex (female, male) and age category $(<40,41-50$, $51-60,>60$ years).

${ }^{\dagger} P$ values for adjusted odds ratios.

CI, confidence interval; ref, reference category. 
opioid misuse and overuse in the United States, such regulations may suggest useful strategies. ${ }^{16}$ Another factor is that, in Japan, opioids are frowned on both culturally and socially. Chronic opioid use is viewed as a criminal act by some. ${ }^{17}$ Furthermore, Japanese patients may be less likely to complain about pain because of strong cultural mores regarding self-attention-a dynamic far less pervasive in the United States. ${ }^{18-20}$ Ironically, however, benzodiazepines are more frequently prescribed in Japan than in any other country. ${ }^{21,22}$

While reporting lower overall opioid use, Japanese respondents were more likely than US respondents to suggest that opioids are indicated for chronic pain. They were also more likely than US respondents to believe opioids are underused. US respondents seemed to have mixed views on prescribing opioids for chronic pain. Though only $58.7 \%$ of US respondents believed that opioids are indicated for chronic pain, $75.6 \%$ indicated that they have prescribed opioids in a chronic pain scenario. This may be the result of awareness by US clinicians of controversy regarding the use of opioids for chronic pain and growing concerns about their efficacy and safety in this setting. These concerns may result in uncertainty regarding optimal opioid prescribing.

Despite system differences, respondents in both the United States and Japan seemed eager to respond to patient requests for pain relief. Respondents in both countries indicated that patient expectations and satisfaction influenced opioid prescribing, especially for chronic pain. Patient satisfaction is a pillar of patient-centered care, and patient satisfaction surveys can be a driving force behind treatment patterns. ${ }^{23}$ However, patient dissatisfaction may not always reflect lower-quality care, especially regarding opioid prescribing. ${ }^{23} \mathrm{Ed}-$ ucating the public about acute and chronic pain management and increasing awareness of the serious side effects of long-term opioid therapy may be important priorities. Patients and clinicians should be aware that alternatives such as physical therapy, cognitive-behavioral therapy, and lifestyle modification can be effective for chronic pain. ${ }^{24,25}$

Less enthusiasm among Japanese prescribers for treating acute pain with opioids may lead to lower initial opioid exposure and thereby contribute to lower rates of long-term use or misuse. Other investigators are exploring strategies that minimize opioid use for acute pain (after surgery) while maintaining good pain control. ${ }^{26}$ A new guideline from the Centers for Disease Control and Prevention notes that long-term opioid use often begins with treatment of acute pain. ${ }^{27}$ Thus, there may be value in greater attention to and better guidelines for optimal opioid prescribing in acute pain.

Limitations of our study include a relatively small sample size, limitation to only one US state (Oregon), focus on a single specialty (Family Medicine), and a relatively low survey response rate. These may limit the generalizability of our results. Unfortunately, we were unable to increase the sample size or response rates (eg, with incentives) because of resource constraints. However, the key findings in our study are congruent with known differences in prescribing rates between the United States and Japan. ${ }^{8}$ Physician survey responses generally tend to be low, averaging only $50 \%$ even under ideal conditions. ${ }^{28}$

The survey design also had limitations. We were unable to conduct conventional psychometric testing because of limited resources, which were devoted to pilot testing, translation, and back translation. We specified the setting in the survey questionnaire as "clinical outpatient," which may have been interpreted variously to refer to a clinic, an urgent care facility, or even an emergency setting; varying interpretations could have affected responses. Our questions on the frequency of opioid use did not quantify the frequency, though most clinicians could only intuitively estimate their frequency of prescribing in any event.

Our findings may contribute to developing more effective US guidelines and policies on opioid use, especially for acute pain. Conversely, Japanese physicians may want to heed caution from the experiences of their counterparts in the United States, where overdose rates and addiction treatment have increased substantially in parallel with increased opioid prescribing.

\section{Conclusion}

Opioids are used far less frequently in Japan than in the United States. Patient expectations and satisfaction may be important influences on opioid prescribing decisions. Less opioid exposure with acute pain, as in Japan, might lead to less use for chronic pain and thereby less overall opioid use. Despite little evidence regarding the efficacy of opioids against chronic pain, many respondents believe they are medically indicated. Nonetheless, US respondents seem concerned about overprescribing opioids, whereas Japanese respondents seem more concerned about underprescrib- 
ing opioids. Experience in the United States suggests caution in this regard. International comparisons may offer useful lessons to clinicians and policymakers in both countries.

The authors thank LeNeva Spires, Publications Manager, Department of Family Medicine, Oregon Health \& Science University, Portland, Oregon, for her editing assistance and help with preparing this article for publication.

To see this article online, please go to: http://jabfm.org/content/ 30/2/248.full.

\section{References}

1. Paulozzi LJ, Jones CM, Mack KA, Rudd RA. Vital signs: overdoses of prescription opioid pain relievers. United States, 1999-2008. MMWR Morb Mortal Wkly Rep 2011;60:1487-92.

2. Okie S. A flood of opioids, a rising tide of deaths. N Engl J Med 2010;363:1981-5.

3. Centers for Disease Control and Prevention. Prescription drug abuse and overdose: public health perspective. October 24, 2012. Available from: http:// www.cdc.gov/primarycare/materials/opoidabuse/docs/ pda-phperspective-508.pdf. Accessed June 4, 2015.

4. Manchikanti L, Abdi S, Atluri S. American Society of Interventional Pain Physicians (ASIPP) guidelines for responsible opioid prescribing in chronic noncancer pain: part I-evidence assessment. Pain Physician 2012 Jul;15(3 Suppl):S1-65.

5. Von Korff M, Kolodny A, Deyo RA, Chou R. Longterm opioid therapy reconsidered. Ann Intern Med 2011;155:325-8.

6. Chou R, Turner JT, Devine EB, et al. The effectiveness and risks of long-term opioid therapy for chronic pain: a systematic review for a National institutes of Health Pathways to Prevention Workshop. Ann Intern Med 2015;17:162:276-86.

7. Chaparro LE, Furlan AD, Deshpande A, MailisGagnon A, Atlas S, Turk DC. Opioids compared with placebo or other treatments for chronic low back pain: an update of the Cochrane review. Spine 2014;39:556-63.

8. Deyo RA, Von Korff M, Duhrkoop D. Opioid for low back pain. BMJ 2015;350:g6380.

9. Kalso E, Edwards JE, Moore RA, McQuay HJ. Opioids in chronic non-cancer pain: systematic review of efficacy and safety. Pain 2004;112:372-80.

10. Von Korff M, Saunders K, Ray GT, et al. De facto long-term opioid therapy for noncancer pain. Clin J Pain 2008;24:521-7.

11. Greberman SB, Wada K. Social and legal factors related to drug abuse in the United States and Japan. Public Health Rep 1994;109:731-7.

12. Johannes CB, Le TK, Zhou X, et al. The prevalence of chronic pain in United States adults: results of an Internet-based survey. J Pain 2010;11:1230-9.
13. Inoue S, Kobayashi F, Nishihara M, et al. Chronic pain in the Japanese community-prevalence, characteristics and impact on quality of life. PLoS One 2015;10:e0129262.

14. Guidance for proper use of medical opioids. Guidance for use and management of opioids in cancer pain treatment. Tokyo: Japanese Ministry of Health, Labour and Welfare; 2012. Available from: http:// www.mhlw.go.jp/bunya/iyakuhin/yakubuturanyou/ other/iryo tekisei guide.html.

15. Hisamitsu Pharmaceutical and Kyowa Hakko Kirin Co., Ltd. E-learning website [in Japanese]. Available from: http://www.jshp.or.jp/cont/14/0703-2-2.pdf. Accessed November 30, 2016.

16. Kuehn B. FDA tightens indications for using longacting and extended-release opioid to treat chronic pain. JAMA 2013;310:1547-8.

17. Yamaguchi S, Kitajima T, Donald RT. Prevention and treatment of opioid abuse and addiction while managing pain in non-cancer patients [article in Japanese]. Pain Clinic 2010;31:1459-75.

18. Free MM. Cross-cultural conceptions of pain and pain control. Proc (Bayl Univ Med Cent) 2002;15:143-5.

19. Streltzer J, Wade TC. The influence of cultural group on the under treatment of postoperative pain. Psychosom Med 1981;43:397-403.

20. Ortega RA, Youdelman BA Havel RC. Ethnic variability in the treatment of pain. Department of Surgery Faculty Papers. Paper 11, November 1999. Available from: http://jdc.jefferson.edu/surgeryfp/11.

21. Hirooka T. Excessive prescribing of hypnotic and anxiolytic drugs in Japan [article in Japanese]. Nihon Rinsho 2015;73:1049-56.

22. Nakao M, Takeuchi T, Yano E. Prescription of benzodiazepines and antidepressants to outpatients attending a Japanese University hospital. Int J Clin Pharmacol Ther 2007;45:30-5.

23. Zgierska A, Millder M, Rabago D. Patient satisfaction, prescription drug abuse and potential unintended consequences. JAMA 2012;307:1377-8.

24. Hayden J, van Tulder MW, Malmivaara A, Koes BW. Exercise therapy for treatment of non-specific low back pain. Cochrane Database Syst Rev 2005; (3):CD000335.

25. Kamper SJ, Apeldoorn AT, Chiarotto A, et al. Multidisciplinary biopsychosocial rehabilitation for chronic low back pain. Cochrane Database Syst Rev 2014;(9):CD000963.

26. Stanek JJ, Renslow MA, Kalliainen LK. The effect of an educational program on opioid prescription patterns in hand surgery: a quality improvement program. J Hand Surg Am 2015;40:341-6.

27. Dowell D, Haegerich TM, Chou R. CDC guideline for prescribing opioids for chronic pain-United States, 2016, MMWR Recomm Rep 2016;65:1-49.

28. Asch DA, Jedrziewski MK, Christakis NA. Response rate to mail surveys published in medical journals. J Clin Epidemiol 1997;50:1129-36. 